\title{
Design and development of PWM switching for 5-level multiphase interleaved DC/DC boost converter
}

\author{
A.F.H.A.Gani, A.A.Bakar, A. Ponniran, M.Hussainar, M.A.N.Amran \\ Department of Electrical Power Engineering, Faculty of Electrical and Electronic Engineering, \\ University Tun Hussein Onn Malaysia, Malaysia
}

\begin{abstract}
Article Info
Article history:

Received Jan 10, 2019

Revised May 1, 2019

Accepted Jul 1, 2019

\section{Keywords:}

Field-programmable gate array Interleaved technique Multiphase boost converter Pulse width modulation Very high description language

ABSTRACT

The continuously increasing demand for control on electric power equipment has led to the rapid technological development in various applications such as renewable energy, electric drives, and communication. Pulse Width Modulation (PWM) switching is an important technique to control the output voltage. PWM signals can either be generated using digital controller or analog controller. Digital controllers are widely used to generate PWM signals due to their reliability in solving complex algorithms within short amount of time. Multiphase boost converter is capable to overcome high input current ripple, current stress and semiconductor losses in conventional boost converter. This paper proposes a PWM switching scheme for multiphase interleaved converter using Field Programmable Gate Array (FPGA). The proposed switching scheme uses PWM switching technique that is implemented by programming Altera DE2-70 board. The duty cycle can be easily adjusted using assigned switches on the Altera board. For validation, switching frequency was set to $100 \mathrm{kHz}$, and then switching signal was observed using oscilloscope.
\end{abstract}

Copyright $\odot 2020$ Institute of Advanced Engineering and Science. All rights reserved.

\section{Corresponding Author:}

\author{
A.A. Bakar, \\ Department of Electrical Power Engineering, \\ Faculty of Electrical and Electronic Engineering, \\ University Tun Hussein Onn Malaysia, \\ Parit Raja, Batu Pahat, Johor, Malaysia. \\ Email: afarul@uthm.edu.my
}

\section{INTRODUCTION}

DC/DC converters are commonly applied in fields of renewable energy, automotive, and communication. There are types of DC/DC converters such as buck, boost, buck-boost, Sepic, Cuk and Flyback [1]. Conventional or single-phase DC/DC converters have certain limitations such as high current stress, high input current ripple, and less efficiency [2]. Another drawback is high conduction loss in the switching devices, which is a major constraint since it affects the output power of the converter [3].

One promising solution is by using DC/DC converters with multiphase configuration. It is basically a combination of conventional DC/DC converter in parallel arrangement. There are advantages of using multiphase configurations, such as reduction of current stress, high current output, low conduction loss, and high efficiency [4-8]. Besides, the size and rating of the components are reduced due to the split of input current into each circuit path. Basically, the performance of multiphase configurations depends on the PWM switching schemes. Multiphase DC/DC converter with interleaved switching technique is able to reduce input current ripple. Interleaved techniques means all power stages are operated in the phase, shifted to each other with the same frequency and duty cycle [9]. By using interleaving technique, the PWM switching signals in each phase can be operated in non-overlapped or overlapped conditions. When the multiphase is operated in non-overlapped conditions, minimum input current ripple can be achieved [10]. Nonetheless, the input 
current ripple will still linearly increase as the switching signals are overlapped. Therefore, suitable duty cycle has to be considered in order to gain non-overlapped conditions. Thus, designation of PWM switching signals plays an important role in controlling the switches to solve those issues.

PWM switching is widely used in power converters, to emit signals to trigger the switch by turning on and turning off the switch [11]. Therefore, the current flowing through the switch can be controlled by manipulating the PWM switching signals. The PWM signals either can be generated using analog or digital controller. Analog circuit requires a large number of passive components, which is directly proportional to the complexity of the switching signals [12]. This is somewhat a limitation that reduces the system reliability and increases circuit complexity and space requirements. Thus, it is desirable to lessen complex mathematical operation due to the limitation in computational capability [13]. Moreover, analog system is hardly to configure without changing its hardware circuit [14].

Nowadays, digital circuits are more widely used compared to analog circuits. Digital systems can be operated in complex control strategies with powerful mathematical algorithms [15]. Moreover, complex control can be realized in short time by using supreme computational software. The most common digital controllers are Digital Signal Processing (DSP) and Field Programmable Gate Arrays (FPGA).

DSP commonly is used for solving complex mathematical algorithm with floating points operations, as in $[16,17]$. This system operates in series, thus requires multiple DSP in order to operate for parallel circuit. PWM signals are less accurate when high switching frequency is applied. Compared to DSP controller, FPGA is more suitable for operation of high switching frequency due to the accuracy of its PWM signals. Besides, this controller is able to operate at the same time in the parallel circuit [18-20]. Thus, space areas can be reduced, as well as the cost of the controller.

This paper highlights the design and development of PWM switching signals for 5-level multiphase interleaved DC/DC converter. Initially, each switching signals range is clearly identified to avoid overlapping of signals. The switching signals are designed using Quartus II software. The signals are set at 60 degrees out of phase to each other. The duty cycle can be set by using assignment pins synchronizing to an internal counter.

\section{PRINCIPLE OF 5-LEVEL MULTIPHASE CONVERTER OPERATION}

In this paper, 5-level multiphase boost converter is proposed. This converter consists of five inductors, five switches and five diodes. Therefore, this converter requires five PWM signals to trigger each switch in the converter. Figure 1 shows the circuit configurations for 5-level multiphase boost converter.

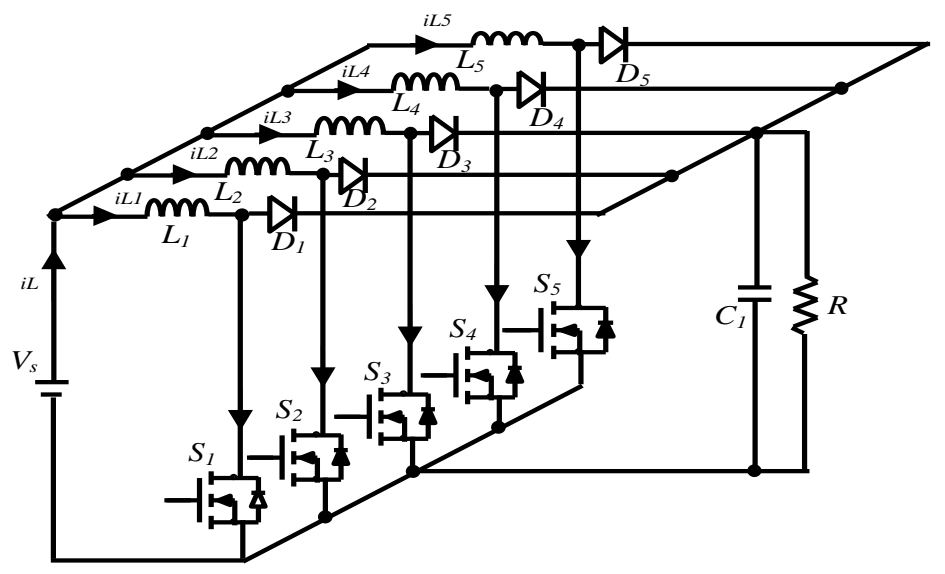

Figure 1. 5-level multiphase configurations

Meanwhile, Figure 2 shows the PWM switching signals for 5-level multiphase boost converter using interleaved technique. The switching signals are phased-shifted by 60 degrees to balance the charging and discharging of inductors over one period of time. Therefore, the inductor current in every phase cancels each other to reduce the input current ripple. The charging time of each inductor can be controlled by adjusting the duty cycle. The charging time of inductor is only increased once the duty cycle has increased. Thus, the output voltage also increases as the charging time of inductor is increased. The output voltage can be calculated by using (1); 


$$
V_{\text {out }}=\frac{V_{\text {in }}}{1-D}
$$

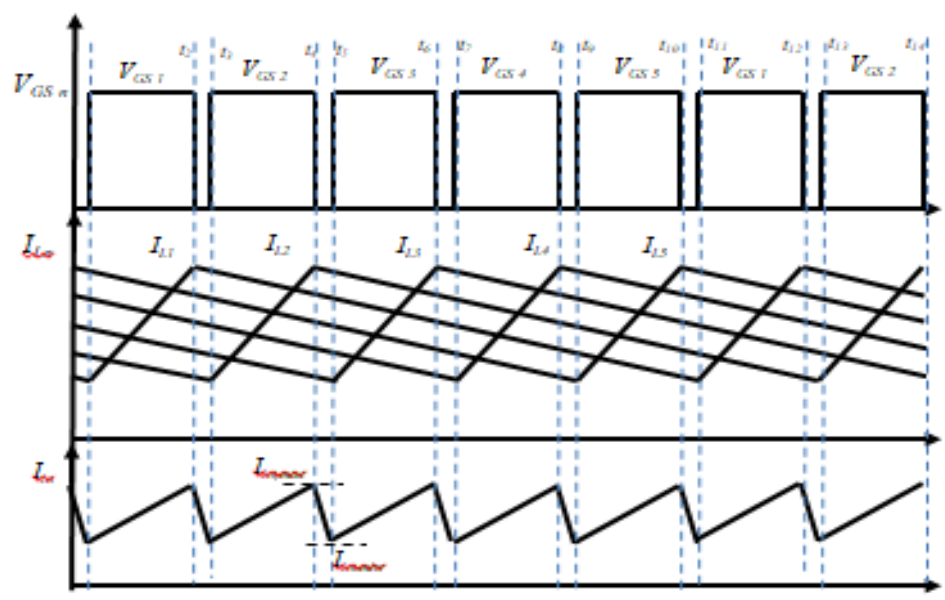

Figure 2. PWM switching signals for 5-level multiphase boost converter

In 5-level multiphase converter, there are 10 modes of operations for one cycle. Table 1 shows the modes operations for 5-level multiphase converter. During stages 1, 3, 5, 7, and 9, only one switch is turnedon, while the other switches are turned-off. Meanwhile, all switches are off during stages 2, 4, 6, 8 and 10.

Table 1. Circuit Parameter

\begin{tabular}{ccc}
\hline Time & Switch, $S_{n}$ & Diode, $D_{n}$ \\
\hline$t_{1}-t_{2}$ (Stage 1) & $S_{1}$ is ON while others are OFF. & $D_{1}$ is OFF while others are ON \\
$t_{2}-t_{3}$ (Stage 2) & All switches $\left(S_{1}, S_{2}, S_{3}, S_{4}, S_{5}\right)$ are OFF. & All diodes $\left(D_{1}, D_{2}, D_{3}, D_{4}, D_{5}\right)$ are ON. \\
$t_{3}-t_{4}$ (Stage 3) & $S_{2}$ is ON while others are OFF. & $D_{2}$ is off while others are ON \\
$t_{4}-t_{5}$ (Stage 4) & All switches $\left(S_{1}, S_{2}, S_{3}, S_{4}, S_{5}\right)$ are OFF. & All diodes $\left(D_{1}, D_{2}, D_{3}, D_{4}, D_{5}\right)$ are ON. \\
$t_{5}-t_{6}$ (Stage 5$)$ & $S_{3}$ is ON while others are OFF. & $\mathrm{D}_{3}$ is OFF while others are ON \\
$t_{6}-t_{7}$ (Stage 6) & All switches $\left(S_{1}, S_{2}, S_{3}, S_{4}, S_{5}\right)$ are OFF. & All diodes $\left(D_{1}, D_{2}, D_{3}, D_{4}, D_{5}\right)$ are ON. \\
$t_{7}-t_{8}$ (Stage 7$)$ & $S_{4}$ is on while others are OFF. & $\mathrm{D}_{4}$ is off while others are ON \\
$t_{8}-t_{9}$ (Stage 8$)$ & All switches $\left(S_{1}, S_{2}, S_{3}, S_{4}, S_{5}\right)$ are OFF. & All diodes $\left(D_{1}, D_{2}, D_{3}, D_{4}, D_{5}\right)$ are ON. \\
$t_{9}-t_{10}$ (Stage 9$)$ & $S_{5}$ is ON while others are OFF & $\mathrm{D}_{5}$ is OFF while others are ON \\
$t_{10}-t_{0}$ (Stage 10$)$ & All switches $\left(S_{1}, S_{2}, S_{3}, S_{4}, S_{5}\right)$ are OFF. & All diodes $\left(D_{1}, D_{2}, D_{3}, D_{4}, D_{5}\right)$ are ON. \\
\hline
\end{tabular}

When the $n$-switch is $\mathrm{ON}$, the inductor current on $n$-phase is charging while the others are discharging. The inductor current rate of change can be calculated using (2) and (3):

$$
\begin{aligned}
& \text { Switch on }=\sum_{k}^{n} \frac{d i_{k}}{d t}=\frac{V_{s}}{L_{k}} \\
& \text { Switch off } \sum_{j}^{n} \frac{d i_{j}}{d t}=\frac{V_{s}-V_{0}}{L_{j}}
\end{aligned}
$$

where $j \neq k$

$k$ is the ON switch and $j$ is the OFF switch

The parameters of the multiphase converter are calculated by using equations in [21]. Some parameters such as input voltage and switching frequency are set to be fixed value in order to calculate the minimum parameters of inductor and capacitor. The minimum parameters of capacitor and inductor value are important to ensure that the converter operates in Continuous Current Mode (CCM) or Discontinuous Current Mode (DCM). In high power applications, CCM is more suitable compared to the DCM due to low input current ripple and low conduction losses. Besides, CCM generates non-pulsate current and the value of input current is not less than or equal to the zero values [22, 23]. Thus, the lifetime of the converter can greatly be improved. Table 2 shows the parameter for 5-level multiphase DC/DC boost converter. 
Table 2. Circuit Parameters

\begin{tabular}{cc}
\hline Parameters & Value \\
\hline Input voltage, $V$ & $15 \mathrm{~V}$ \\
Switching frequency, $f_{s}$ & $100 \mathrm{kHz}$ \\
Inductor, $L$ & $220 \mu \mathrm{H}$ \\
Capacitor, $C$ & $470 \mu \mathrm{F}$ \\
Resistor, $R$ & $150 \Omega$ \\
\hline
\end{tabular}

\section{SIMULATION USING ORCAD PSPICE SOFTWARE}

In this study, OrCAD PSpice software was used to simulate the parameters of the 5-level multiphase DC/DC boost converter before implementation into hardware prototypes. The parame-ters had been set in this software based on calculated parameters. Figure 3 shows the multiphase DC/DC boost converter model using OrCAD PSpice software.

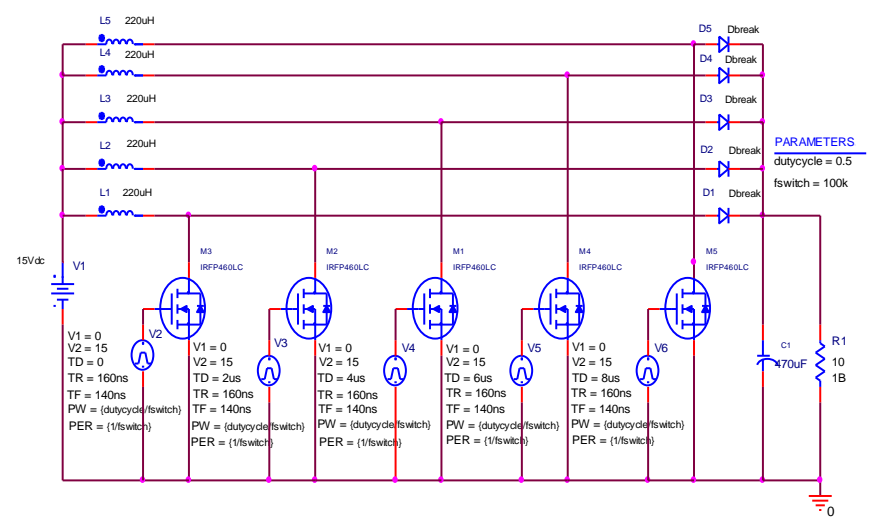

Figure 3. 5-level multiphase DC/DC boost converter model in OrCAD PSpice software

\section{QUARTUS II SOFTWARE}

Quartus II software was used to design the PWM switching signals. This software uses schematics or a hardware description language (HDL) such as Verilog HDL or VHDL. Figure 4 shows a flowchart representing the algorithm workflow of 5-level multi-phase boost converter.

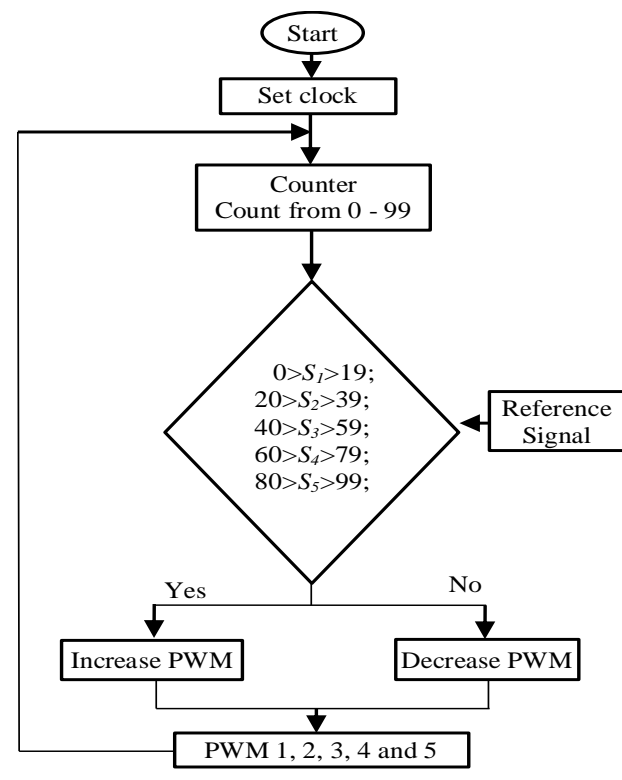

Figure 4. Flowchart of 5-level PWM signal 
Initially, the clock is set by using altpll megafunction block diagram (.vhd). The altpll megafunction block is used to adjust the phase of generated signal to match the phase of an input signal. The input of altpll is connected with $50 \mathrm{MHz}$ internal clock from PIN_AD15 to generate a $10 \mathrm{MHz}$ output. Then, the $10 \mathrm{MHz}$ output frequency is connected to the lpm_counter. The function of lpm_counter is to generate binary counter which operates either in up, down or up/down counter. The counter is set to 7 bits with up-counter. Therefore, the counter will count from 0-99 for one complete cycle; representing $1 \mathrm{~ms}$ period for one cycle for proffered frequency. Output from the lpm_counter will be sent to the comparator block to generate the PWM switching signals. The switching frequency of $100 \mathrm{kHz}$ will be automatically set at the output of lpm_counter. In this study, since the output of lpm_counter was connected to each comparator, and fivephase multiphase boost converter being used, five comparators had been employed.

The comparators function to compare the input and the continuing lpm_counter in order to produce signal for $S_{1}, S_{2}, S_{3}, S_{4}$ and $S_{5}$. The conditions or ranges in each comparator are set by using IF ELSE statement in VHDL coding. The boundaries for each signal are set differently in order to phase-shift the output signals. The maximum on-state for each signal is $1 / 5$ of the main clock. For example, the signal $S_{l}$ is only turned on from counter 0 to 19 , while counter $S_{2}$ is from 20 to 39, counter $S_{3}$ is from 40 to 59 , counter $S_{4}$ is from 60 to 79 , and counter $S_{5}$ is from 80 to 99 . Figure 5 shows the concept of 5 -level interleaved signal using digital technique.

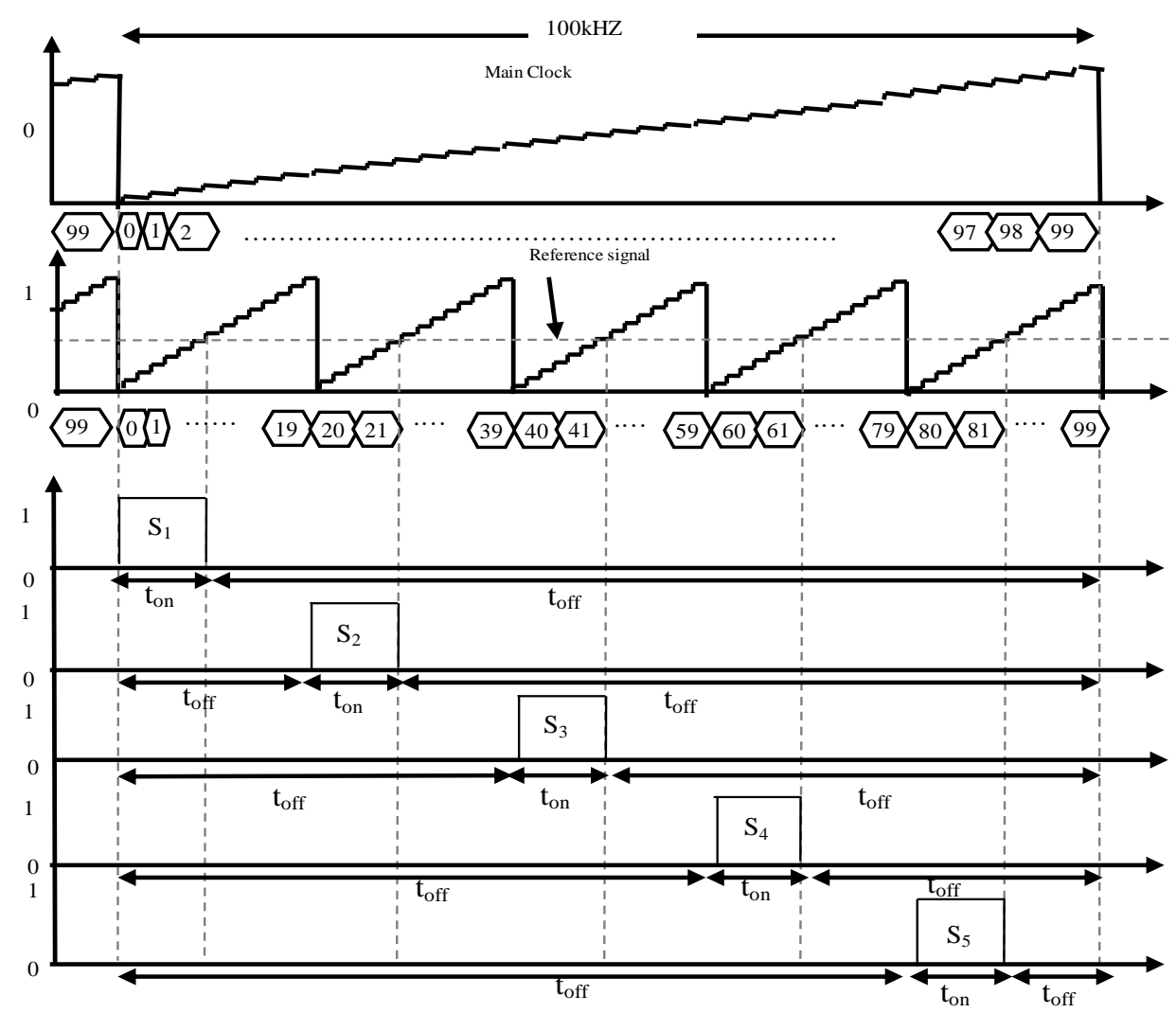

Figure 5. Associated PWM technique using digital implementation for 5-level interleaved signal

Once the compilation of the VHDL code is successful, the VHDL code will be converted into bdf schematic. The block diagram editor allows user to represent the whole system in single diagram. Figure 6 shows a PWM switching signals generator block diagram that has been programmed using Quartus II software. Series of pins are assigned such as input clock, slider switches and input/output. The slider switches are used to adjust the duty cycle.

In this study, the counter was set to 7-bit, therefore, 7 toggle switches had been assigned as the inputs in order to control the duty cycle in the converter. Table 3 shows the pin assignments for 5-phase PWM switching signals program. By referring to pin assignments, the location and direction of input and output connections can be determined. Table 4 shows the toggle switches for the 7-bit counters. Hence, the duty cycle can be manually adjusted by using assigned switches in FPGA board. 


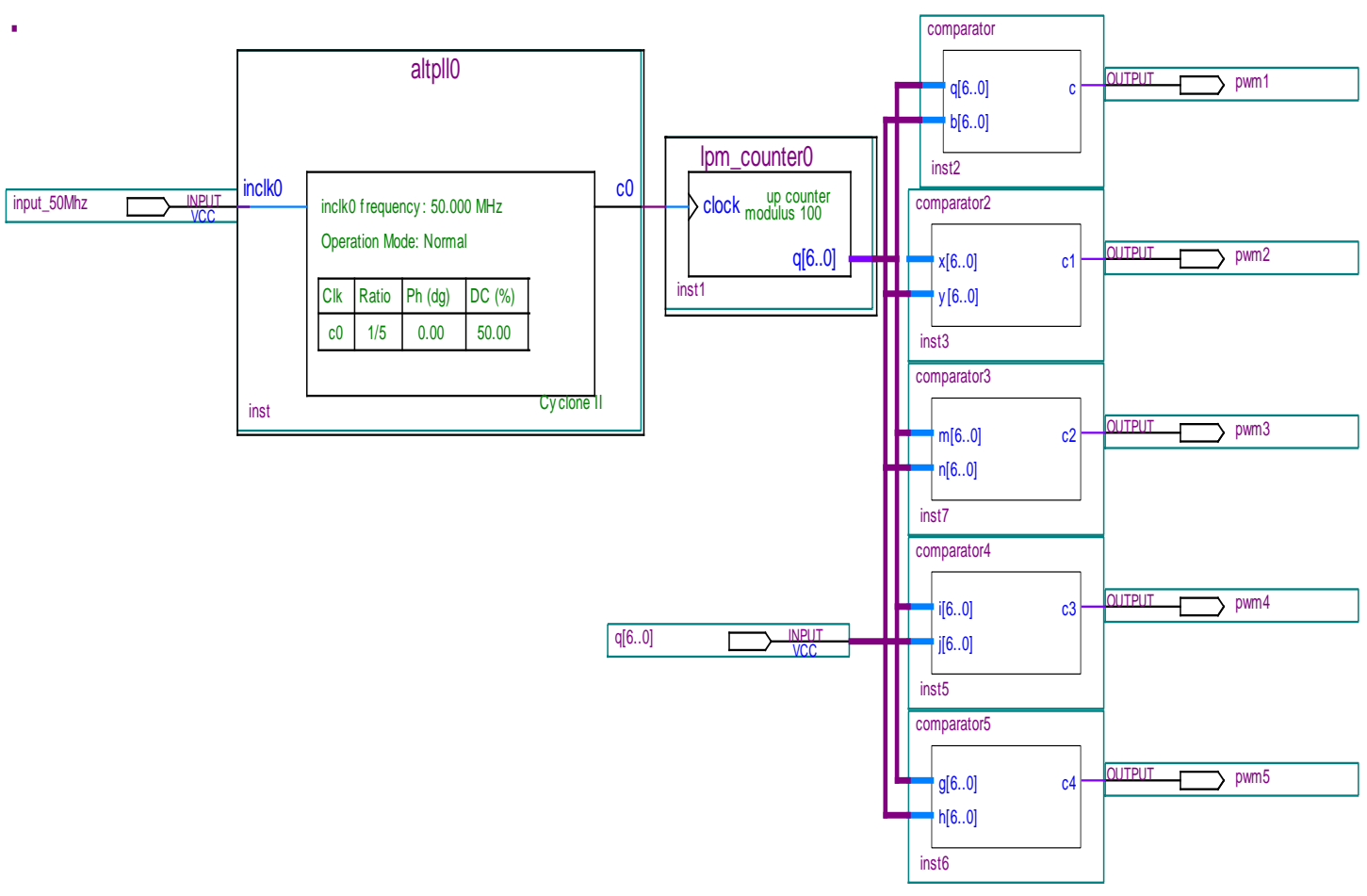

Figure 6. 5-level multiphase boost converter signals generator

Table 3. Pin Assignments for 5-phase PWM Switching Signals Program

\begin{tabular}{ccc}
\hline Node name & Pin location & Description \\
\hline Input_50MHz & PIN_AD15 & 50MHz FPGA internal clock \\
b[0] & PIN_AA23 & Slider switch 0 \\
b[1] & PIN_AB26 & Slider switch 1 \\
b[2] & PIN_AB25 & Slider switch 3 \\
b[3] & PIN_AC27 & Slider switch 4 \\
b[4] & PIN_AC26 & Slider switch 5 \\
b[5] & PIN_AC24 & Slider switch 6 \\
b[6] & PIN_AC23 & General-purpose input/output (GPIO) connection [1] \\
pwm1 & PIN_P30 & General-purpose input/output (GPIO) connection [2] \\
pwm2 & PIN_P29 & General-purpose input/output (GPIO) connection [3] \\
pwm3 & PIN_N29 & General-purpose input/output (GPIO) connection [4] \\
pwm4 & PIN_N28 & General-purpose input/output (GPIO) connection [5] \\
pwm5 & PIN_R27
\end{tabular}

Table 4. Toggle Switches For 7 bits Counters

\begin{tabular}{|c|c|c|c|c|c|c|c|c|}
\hline 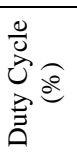 & $\begin{array}{l}2^{6} \\
64\end{array}$ & $\begin{array}{l}2^{5} \\
32\end{array}$ & $\begin{array}{l}2^{4} \\
16\end{array}$ & $\begin{array}{l}2^{3} \\
8\end{array}$ & $\begin{array}{c}2^{2} \\
4\end{array}$ & $\begin{array}{l}2^{1} \\
2\end{array}$ & $\begin{array}{c}2^{0} \\
1\end{array}$ & 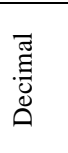 \\
\hline 10 & 0 & 0 & 0 & 1 & 0 & 1 & 0 & 10 \\
\hline 20 & 0 & 0 & 1 & 0 & 1 & 0 & 0 & 20 \\
\hline 30 & 0 & 0 & 1 & 1 & 1 & 1 & 0 & 30 \\
\hline 40 & 0 & 1 & 0 & 1 & 0 & 0 & 0 & 40 \\
\hline 50 & 0 & 1 & 1 & 0 & 0 & 1 & 0 & 50 \\
\hline 60 & 0 & 1 & 1 & 1 & 1 & 0 & 0 & 60 \\
\hline 70 & 1 & 0 & 0 & 0 & 1 & 1 & 0 & 70 \\
\hline 80 & 1 & 0 & 1 & 0 & 0 & 0 & 0 & 80 \\
\hline 90 & 1 & 0 & 1 & 1 & 0 & 1 & 0 & 90 \\
\hline 100 & 1 & 1 & 0 & 0 & 1 & 0 & 0 & 100 \\
\hline
\end{tabular}

In interleaved techniques, the dead-time or blanking time should be considered in order to reduce current spike across the switch during turning-on and turning-off of each switch. Dead-time is a time delay, 
which allows inverting switching signals into turn-off before the other turn-on. In this study, Metal Oxide Semiconductor Field Effect Transistor (MOSFET) was used as the power switch. This type of switch has a gate for charge and discharge time rather than instantly turning on and off. Without dead-time, the PWM switching signals will overlap each other, which means two switches will be turned on for a small period of time. The function of dead-time is to avoid unnecessary heating and high losses to the converter [24-26].

Dead-time is added by reducing the counter division in each comparator. By doing this, the signal's duty cycle will be compromised. For example, when the duty cycle is set at 0.2 , the signal duty cycle should appear at 0.18 when observed using oscilloscope; however, when the fall time and rise time are considered, the signal actually takes the capacity of 0.2 duty cycle.

\section{RESULT AND ANALYSIS}

The output of the Altera DE2-70 was observed using Tektronix TDS2014B four channel oscilloscope. Since the oscilloscope can only read maximum four waveforms, only four waveforms were obtained for five-phase PWM signals.

In Figure 7, $\mathrm{CH} 1$ represents the first PWM signal, $\mathrm{CH} 2$ represents the second PWM signal, $\mathrm{CH} 3$ represents the third PWM signal, and $\mathrm{CH} 4$ represents the fourth $\mathrm{PWM}$ signal. From the waveforms captured by Tektronix TDS2014B, it can be observed that all the PWM signals had been turned on in interleaving manner with the switching frequency of $100 \mathrm{kHz}$. The voltage for PWM signals from Altera DE2-70 board was $3.33 \mathrm{~V}$.

The gate driver was used to boost the voltage magnitude of the signals from $3.33 \mathrm{~V}$ to $15 \mathrm{~V}$ to make sure that the signals able to trigger the MOSFET. The gate and source pin of the MOSFET were connected to the output of the gate driver for control, so that the PWM signals would control the ON and OFF period of the MOSFET with the reference duty cycle. Figure 8 shows the PWM signals output from the gate driver.

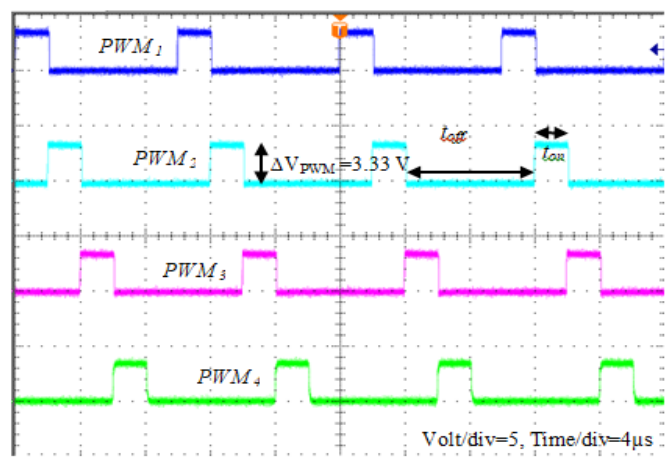

Figure 7. PWM signals output from Altera

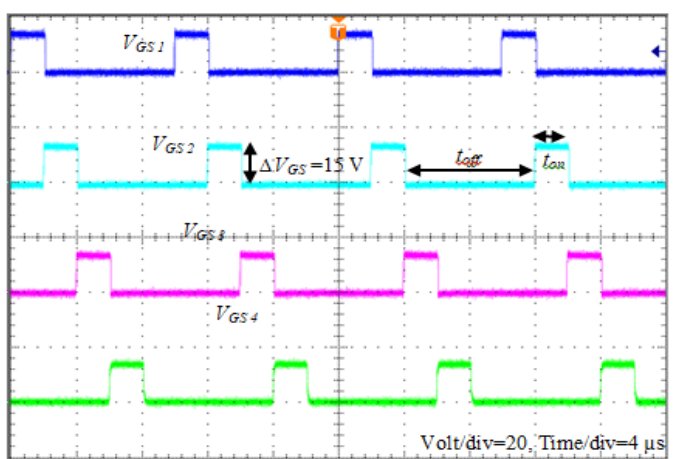

Figure 8. PWM signal output from gate driver

Figure 9 shows the PWM signals without dead-time and with dead-time. As shown in Figure 9(a), the crossover between PWM 1 and PWM 2 caused spike to the signals. Meanwhile, no spike was occur when dead time is implements, as shown in Figure 9(b).

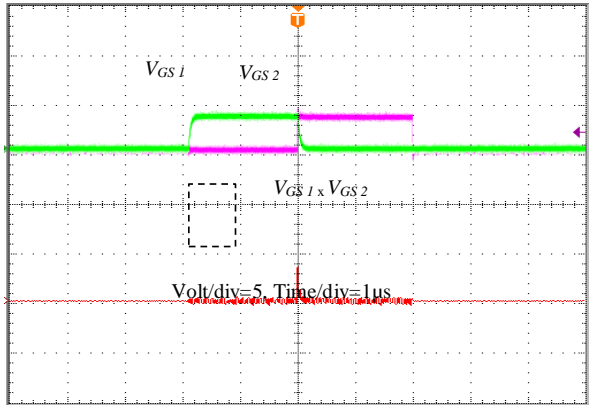

(a)

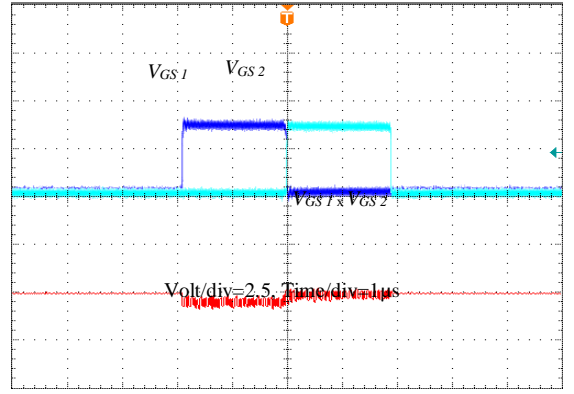

(b)

Figure 9. PWM signals (a) without dead-time and (b) with dead-time 
Table 5. Output Voltage in Simulation and Experimental

\begin{tabular}{ccc}
\hline Duty Cycle, $D$ & \multicolumn{2}{c}{ Output Voltage, $V_{o}$} \\
& Simulation $(V)$ & Experimental $(V)$ \\
\hline 0.05 & 17.29 & 16.20 \\
0.10 & 18.72 & 17.60 \\
0.15 & 20.66 & 18.90 \\
0.20 & 22.73 & 20.80 \\
\hline
\end{tabular}

The experimental setup for 5-level multiphase boost converter are carried by using Altera DE2-70 as a microcontroller. From the results in Table 5, it can be seen that the values of the output voltage produced by experiment and simulation slightly differ, which might be due to factors such as switching losses, conduction losses and number of phase. The inserted dead-time also significantly changed the behavior of the actual duty cycle, causing a small voltage drop compared to simulation. Nonetheless, the results show that the multiphase converter can work correctly theoretically; indicating that the proposed design can be implemented as part of multiphase converter, in addition to power circuit using PWM as its control scheme.

\section{CONCLUSION}

This paper has presented a specifically designed PWM switching signals to meet the needs of the multiphase DC/DC boost converters. The PWM switching signals are generated by using VHDL programming in FPGA controller. Other programming languages such as Verilog, $\mathrm{C}$ languages and logic form are applicable with the FPGA controller. By using interleaved technique, the PWM switching signals are set to phase-shift in each level. This technique can be realized by setting the reference signals in every comparator. Comparison between the simulation and experimental results shows a small difference in output voltage.

\section{ACKNOWLEDGEMENTS}

The authors would like to express their deepest appreciation to Universiti Tun Hussein Onn Malaysia for supporting this research under GPPS Vot H299 and TIER 1 Vot U858 research grants.

\section{REFERENCES}

[1] N. H. Baharudin, T. M. N. T. Mansur, F. A. Hamid, R. Ali, and M. I. Misrun, "Topologies of DC-DC converter in solar PV applications," Indones. J. Electr. Eng. Comput. Sci., vol. 8, no. 2, pp. 368-374, 2017.

[2] M. A. Harimon, A. Ponniran, A. N. Kasiran, and H. H. Hamzah, "A Study on 3-phase Interleaved DC-DC Boost Converter Structure and Operation for Input Current Stress Reduction," Int. J. Power Electron. Drive Syst., vol. 8, no. 4, pp. 1948-1953, 2017.

[3] G. Cajazeiras Silveira, F. Tofoli, L. D. Santos Bezerra, and R. P. Torrico-Bascope, "A Nonisolated DC-DC Boost Converter with High Voltage Gain and Balanced Output Voltage,” IEEE Trans. Ind. Electron., vol. 0046, no. 12, pp. 1-1, 2014.

[4] A. A. Bakar, M. U. Wahyu, A. Ponniran, and T. Taufik, "Simulation and Analysis of Multiphase Boost Converter with Soft-Switching for Renewable Energy Application," Int. J. Power Electron. Drive Syst., vol. 8, no. 4, pp. 1894-1902, 2017.

[5] A. N. Kasiran, A. Ponniran, A. A. Bakar, M. H. Yatim, M. K. R. Noor, and J. N. Jumadril, "Implementation of Resonant and Passive Lossless Snubber Circuits for DC-DC Boost Converter," Int. J. Eng. Technol., vol. 7, no. 4.30, p. 246, 2018.

[6] G. Y. Choe, H. S. Kang, B. K. Lee, and W. Y. Lee, "Design Consideration of Interleaved Converters for Fuel Cell Applications," Proceeding Int. Conf. Electr. Mach. Syst. ICEMS 2007, pp. 238-243, 2007.

[7] F. Sobrino-Manzanares and A. Garrigos, "Bidirectional, interleaved, multiphase, multidevice, soft-switching, FPGA controlled, buck-boost converter with PWM real-time reconfiguration," IEEE Trans. Power Electron., vol. 33, no. 11, pp. 9710-9721, 2018.

[8] B. S. Revathi and P. Mahalingam, "Non-isolated high gain DC - DC converter with low device stress and input current ripple," IET Power Electron. Res., no. ii, pp. 2553-2562, 2018.

[9] M. Ganta, P. Nirupa, T. Akshitha, and R. Seyezhai, "Design and Simulation of PWM Fed Two-Phase Interleaved Boost Converter for Renewable Energy Source," Internantional J. Electr. Electron. Data Commun., vol. 1, no. 1, pp. 18-23, 2013.

[10] C. Wang, C. Lin, S. Hsu, C. Lu, and J. Li, "Analysis, Design and Performance of a Zero-Current- Switching PulseWidth-Modulation Interleaved Boost DC / DC Converter," IET Power Electron., no. July 2013, pp. 2437-2445, 2014.

[11] Y. M. Buswig, A. K. Othman, N. Julai, S. S. Yi, and ..., "Voltage Tracking of a Multi-Input Interleaved Buck-Boost DC-DC Converter Using Artificial Neural Network Control,” J. ..., no. December, 2018. 
[12] R. Srivastava, Y. K. Chauhan, and B. Kumar, "Generation of PWM using verilog in FPGA," Int. Conf. Electr. Electron. Optim. Tech. ICEEOT 2016, no. March, pp. 4593-4597, 2016.

[13] E. Monmasson, L. Idkhajine, I. Bahri, M. W. Naouar, and L. Charaabi, "Design methodology and FPGA-based controllers for power electronics and drive applications," Proc. 2010 5th IEEE Conf. Ind. Electron. Appl. ICIEA 2010, pp. 2328-2338, 2010.

[14] C. Buccella, C. Cecati, and H. Latafat, "Digital Control of Power Converters-A Survey," IEEE Trans. Ind. Informatics, vol. 8, no. 3, pp. 437-447, 2012.

[15] B. Rashidi, "FPGA Implementation of Digital Controller for Simple and Maximum Boost Control of Three Phase Z-Source Inverter,” Int. J. Inf. Technol. Comput. Sci., vol. 5, no. 4, pp. 85-95, 2013.

[16] A. A. Bakar, W. M. Utomo, T. Taufik, and A. Ponniran, "Modeling of FPGA- and DSP-Based Pulse Width Modulation for Multi-Input Interleaved DC / DC Converter,” vol. 14, no. February, pp. 79-85, 2019.

[17] M. Farhat, O. Barambones, and L. Sbita, "Efficiency optimization of a DSP-based standalone PV system using a stable single input fuzzy logic controller," Renew. Sustain. Energy Rev., vol. 49, pp. 907-920, 2015.

[18] C. A. Sepulveda, J. A. Munoz, J. R. Espinoza, M. E. Figueroa, and C. R. Baier, "FPGA v/s DSP performance comparison for a VSC-based STATCOM control application," IEEE Trans. Ind. Informatics, vol. 9, no. 3, pp. 1351-1360, 2013.

[19] N. A. Rahim and Z. Islam, "Field Programmable Gate Array-Based Pulse-Width Modulation for Single Phase Active Power Filter," Am. J. Appl. Sci., vol. 6, no. 9, pp. 1742-1747, 2009.

[20] M. Shahbazi, E. Jamshidpour, P. Poure, S. Saadate, and M. R. Zolghadri, "Open-and short-circuit switch fault diagnosis for nonisolated DC-DC converters using field programmable gate array," IEEE Trans. Ind. Electron., vol. 60, no. 9, pp. 4136-4146, 2013.

[21] T. N. Ajit, "Two Stage Interleaved Boost Converter Design and Simulation in CCM and DCM," vol. 3, no. 7, pp. 847-851, 2014.

[22] O. Lopez-Santos, L. Martinez-Salamero, G. Garcia, H. Valderrama-Blavi, and D. A. Zambrano-Prada, "SteadyState Analysis of Inductor Conduction Modes in the Quadratic Boost Converter," IEEE Trans. Power Electron., vol. 32, no. 3, pp. 2253-2264, 2017.

[23] B. Sri Revathi and M. Prabhakar, "Non Isolated High Gain DC-DC Converter Topologies for PV Applications - A Comprehensive Review,” Renew. Sustain. Energy Rev., vol. 66, pp. 920-933, 2016.

[24] W. Yan, C. Pi, W. Li, and R. Liu, "Dynamic dead-time controller for synchronous buck DC-DC converters," Electron. Lett., vol. 46, no. 2, p. 164, 2010.

[25] J. Seung-G, L. Bang-sup, K. Kyung-seo, and P. Min-ho, "The Analysis and Compensation of Dead Time Effects in PWM Inverters," IEEE Trans. Ind. Electron., vol. 38, no. 2, pp. 108-114, 1991.

[26] Y. K. Lin and Y. S. Lai, "Dead-time elimination method and current polarity detection circuit for three-phase PWM-controlled inverter,” 2009 IEEE Energy Convers. Congr. Expo. ECCE 2009, vol. 56, no. 6, pp. 83-90, 2009.

\section{BIOGRAPHIES OF AUTHORS}

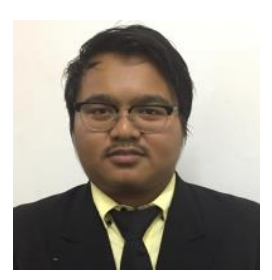

Ahmad Faiz Hilmi Abdul Gani was born in Kedah, Malaysia in 1995. He received the Bachelor's degree in electrical engineering from Universiti Tun Hussein Onn Malaysia (UTHM), Parit Raja, Batu Pahat, Johor, Malaysia in 2018. He is currently working toward the M.S degree in Electrical Engineering at UTHM. His research interest are the area of DC/DC converters, controller design and renewable energy.

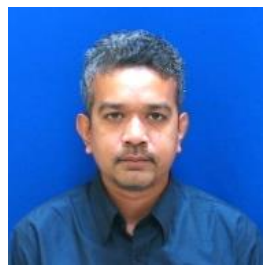

Afarulrazi Abu Bakar was born in Johor, Malaysia on May 18, 1980. He received his M.Eng. (Electrical) from Universiti Tun Hussein Onn Malaysia (UTHM) in 2007 and B.Eng. (Electrical) from Universiti Teknologi Mara (UiTM) in 2004. He has been working as a lecturer at the Department of Electrical Power Engineering, Faculty of Electrical and Electronic Engineering, UTHM, since 2007. Previously, he was a visiting scholar at Electrical Engineering Department, California State University, California, USA, in 2015. His research interests are the areas of renewable energy, DC/DC converters, multiple-input converters, multiphase converters, resonant converters, and controller design.

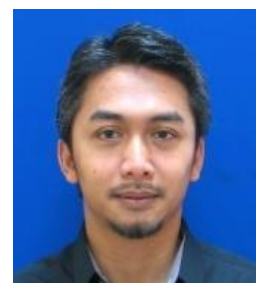

Asmarashid Bin Ponniran received the bachelor's degree in electrical engineering from Universiti Tun Hussein Onn Malaysia, Parit Raja, Malaysia, in 2002, and the master's degree in electrical engineering (power) from Universiti Teknologi Malaysia, Johor Bahru, Malaysia, in 2005. Then, he received the Ph.D degree in electrical engineering from the Nagaoka University of Technology, Nagaoka, Japan. He is currently working as lecturer with Universiti Tun Hussein Onn Malaysia. His research interest includes power converter, underground power cable in distribution side, and demand side management of power consumption 


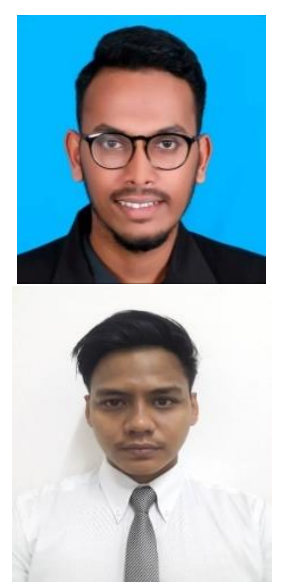

Mustapa Hussainar was born in Johor, Malaysia in 1995. He received the Bachelor's degree in electrical engineering from Universiti Tun Hussein Onn Malaysia (UTHM), Parit Raja, Batu Pahat, Johor, Malaysia in 2019.

Mohd Azlee Noor Amran was born in Selangor, Malaysia in 1995. He received the Bachelor's degree in electrical engineering from Universiti Tun Hussein Onn Malaysia (UTHM), Parit Raja, Batu Pahat, Johor, Malaysia in 2019. He is currently working toward the M.S. degree in Electrical Engineering at UTHM. His current research interests include the area of power electronics and control. 